DOI: $10.2478 /$ rjp-2020-0003

\title{
A VIEW ON PATIENTS WITH SOMATIC OR PAINFUL CONDITIONS
}

Marilia Aisenstein ${ }^{3}$

\begin{abstract}
The psychoanalytic treatment of patients suffering from a somatic disease or from chronical pain covers an important field. When confronted with those patients the psychoanalyst needs a theoretical background and technical adjustments. This paper exposes the theoretical corpus of the Paris School of Psychosomatics and relates three clinical cases.
\end{abstract}

Keywords: body, soma, regression, mentalization, operational thinking, essential depression.

\section{Introduction}

I will begin this article with a history survey of the psychosomatic approach of the Paris School followed by a brief outline of our theory. I will then relate three clinical vignettes.

Psychiatry and medicine have long questioned the connection between body and mind. The question of whether the soul and the body are of the same substance has haunted all Western philosophy. After Spinoza, materialist monism supplanted the psyche-soma dualism and prepared the ground for the answer given by Freud, namely, that it is not the case of a clash between a body and its desires on the one hand and a psyche and its reasons on the other, but rather that contradictory forces can be in opposition in the same areas of the body...

The birth of psychoanalysis is linked to the study of conversion hysteria. It is interesting to note that Freud never wrote in terms of psychogenesis, but rather evoked the idea of an organ being forced to serve two masters at once, thus giving meaning to the conversion symptom.

\footnotetext{
${ }^{3}$ Paris Psychoanalytical Society \& Hellenic Psychoanalytical Society; marilia.aisenstein@gmail.com
} 
The word "psychosomatic" hardly appears in his writings, but the history of this term deserves to be retraced. It appeared for the first time in the $18^{\text {th }}$ century. J.C. Heinroth (1773-1843), an alienist and psychiatrist who was part of the vitalist movement inaugurated by Marie-François Xavier Bichat (1771-1802), seems to have forged it to describe certain "somato-psychic" or "psychosomatic" factors in a publication on the influence of passions and sexuality in cases of tuberculosis and epilepsy.

After falling into obsolescence for a long time, the word was taken up a century later by Felix Deutch (1894-1963), a disciple of Freud and the first psychoanalyst who envisaged the possibility of treating somatic disorders psychoanalytically. Deutch nevertheless introduced a hyphen, the word "psychosomatic" becoming "psycho-somatic", but he seemed to remain caught up in a dualism in search of reciprocal influences.

Freud's relationship with psychosomatic phenomena is complex. On the one hand, by replacing the psyche-soma dualism with the dualism of the drives, he immediately placed psychoanalysis within a substantial and philosophical monism. (The drive is a fundamental Freudian concept; it is vital energy, the initial somatic force that moves the psychic apparatus. There are two antagonistic drives: libido and unbinding). On the other hand, he seemed very hesitant to engage in this line of research. One can indeed detect in him a real indecision. From the theoretical point of view, he argued that only psychoanalysis could allow us to understand the "relations" between the body and the mind. Nevertheless, from his silence in 1913 when Federn presented a case of asthma, and also his reluctance to encourage psychoanalysts to look into somatic problems, it is obvious that he hesitated in giving any real impetus to psychosomatic research.

Freud turned out to be monistic in his studies and theoretical conclusions, but dualistic when confronted with clinical practice. He later confided in correspondence to Ferenczi that psychoanalysts did not yet have the necessary training to tackle these problems.

However, two short passages, one in "On narcissism: an introduction" (Freud, 1914, pp. 85-86), in which he evokes the necessary flowing back of narcissistic libido towards the ego in the patient, and another in Beyond the Pleasure Principle (Freud, 1920, p. 33, lines 37-39), where he reflects on the disappearance of acute mental symptomatology during the outbreak of an intercurrent somatic disease, and notes, as an aside, that it must be a question of the modes of distribution of the libido, seem to indicate the existence of an almost premonitory vision of psychosomatic research in Freud's work. 
Through these "short" remarks, the founder of the psychoanalytic method laid the foundations of the psychosomatic approach that is today that of the so-called Paris School.

Historically the foundations of psychosomatics as a discipline are based on the clinical observations of the psychoanalysts F. Deutsch, G. Groddeck, and S. Ferenczi. The first systematic studies were conducted in the USA where Franz Alexander founded the "Chicago School of Psychosomatic Medicine" with Helen Flanders Dunbar. It is also interesting to note that two major life insurance companies funded the early research of Alexander and his group.

For him, there is an evolving identity between psychical processes and physiological factors, seen from a psychodynamic perspective. Psychic manifestations are immediately included in the physiology of the organic functions corresponding to the satisfaction of vital needs. They are expressed in attitudes of tonus and posture based on a dynamic of tensions and discharges.

The infant, and later the young child, receives signals to which he responds through bodily activity. The main organic functions correspond to three schemas, incorporation, retention and elimination, which are vectors underlying human and relational activities. Based on the development of the organism, mental processes are differentiated and integrated in the course of maturation.

The hypotheses of Alexander and Dunbar aimed to link somatic syndromes, which they called psychosomatic, to specific conflicts, thereby defining "psychosomatic diseases". This is contrary to the views of the Paris School which claims that it is the human being who is "psychosomatic", while the symptom is without symbolic meaning, albeit linked to the genetic fragility of the subject.

It is regrettable that nowadays American psychoanalysis seems to have lost interest in the work of the Chicago School.

During the 1960s, in a different vein of research, Pierre Marty and Michel de M'Uzan, in France, and Sifneos and Namias in the USA, described respectively "operational thinking" (la pensée opératoire") and "alexithymia", to account for a negative psychopathology characterized by the apparent absence of affective and fantasy life frequently associated with somatic disorders. Working at Clermont's psychiatric hospital in the winter of 1942, in the midst of the war, during an exceptionally cold winter, Pierre Marty was struck by the low level of impact on chronic psychotics resulting from scarcity of food and lack of heating, whilst their caregivers lost weight and fell ill. He drew the conclusion that the intense psychic work of psychosis 
protected the body. With Michel de M'Uzan, Michel Fain and Christian David, he began to think about the apparent absence of psychic signals in critically ill and hospitalized patients.

Founded by psychoanalysts, the "Paris School of Psychosomatics" was founded in 1962. It was long considered as dissident group by many colleagues. Yet psychosomatic treatment, the application of psychoanalysis to the disorders of the body, should be our first vocation. Indeed, the dream, a privileged object of psychoanalytic science, is conceivable only as a physiological function included in a clinical approach to sleep. The dream thus testifies to the somatic, bodily dimension, present on several levels in any psychoanalytic approach.

In defining a "psychosomatic order", the work of Pierre Marty, like the ample literature that we owe to first generation psychosomaticians (Pierre Marty, Michel de M'Uzan, Michel Fain, Christian David), is of crucial importance. The main interest of this work is to have drawn the attention of the ordinary psychoanalyst to the economy, the modalities of distribution of the libido, as well as to the importance of the texture and variability of mental functioning. The notions of changes and differences of regime were superimposed on those of structure or organization. This fundamental aspect will be developed further on.

One difficulty faced by psychoanalysis in general lies in the impossibility of relying on a classical psychiatric or psychological epistemology, psychoanalytic semeiology having its own singularity.

More complicated still was the task of the Paris School pioneers, who were obliged to confront a "blank" or "hollow" semeiology, and to take into account clinical presentations of a great diversity, but one characteristic of which often consisted in a display of excessive normality.

The keystone of Marty's theoretical edifice resides in the assumption that our mental apparatus has the function of managing the constant traumatic excitations of life. If this psychic apparatus is faulty or overloaded, the excitation must find other paths of discharge, which will be via behaviour or the body. The somatic path thus provides a solution.

These hypotheses led to the creation of new concepts, such as those of "essential depression", "progressive disorganization", "operational thinking" (pensée opératoire), now adopted by the psychoanalytic community as a whole. Similarly, the necessity of clinical practice and its phenomenology led to the use of different nosographic categories, which are sometimes questionable, such as those of so-called "behavioural" neuroses. The field 18 
thus inaugurated left open the possibility of theoretical research into Freudian metapsychology as well as into its variables and its borders - essentially between psychosis and somatosis, as well as borderline states - a deepening that is crucial in my eyes because only thus is it possible to avoid a harmful fragmentation of domains and knowledge.

\section{Some fundamental concepts for psychosomatic clinical practice}

Contrary to the medical psychosomatic approach, which looks at the patient in terms of his (or her) illness, the psychoanalytic approach looks at him by locating, in his psychical functioning, a process of somatization. Thus, psychosomatic practice only emerges through the filter of the relationship established by the psychoanalyst with his or her sick patient.

A process of somatization is a chain of psychic events that promote the development of somatic illness. Two modalities of the somatization process are usually distinguished: the process of somatization through regression and the process of somatization through drive unbinding. The term "drive unbinding" calls for explanation. According to Freudian theory the psychic apparatus is set in motion by the drives = the vital energy, consisting of a mixture of libido and unbinding, and therefore destructiveness. If the drives are subject to unbinding, each drive evolves on its own account putting mental functioning in danger.

\section{The concept of mentalization}

This is a notion conventionally used by psychosomatician psychoanalysts that covers the whole field of psychic elaboration. Mentalization therefore mainly concerns representative activity (representations are the psychic images or videos that animate us; psychic life is based primarily on images which are then associated with words) of the individual. Insofar as the work of binding (i.e. the connection between them) of representations takes place in the preconscious system, evaluation of the quality of mentalization and that of the quality of the preconscious are almost equivalent.

For Pierre Marty, mentalization may be considered in terms of three axes, each representing one of the dimensions of the activity of representations: its density, its fluidity and its permanence:

Density refers to the number of layers of representations accumulated and stratified during the individual's history.

Fluidity concerns the quality of the representations and their circulation, through the different epochs as well as currently. 
Permanence concerns the availability, at all times, of all of its representations both quantitatively and qualitatively.

\section{The processes of somatization via regression}

This is a process that usually leads to benign and reversible somatic crises such as, for example, asthma, cephalalgic or rachialgic attacks, ulcerative, colitic or hypertensive crises. These are somatizations that often return in the same form in the same individual.

These somatizations generally occur in subjects whose psychic functioning is organized in a neurotic-normal mode. Their mentalization is usually satisfactory or little altered. Here, somatisations occur following variations of psychic functioning that Marty described as irregularity of mental functioning.

\section{The processes of somatization as a result of drive unbinding}

This means that the drives of self-preservation are no longer able to bind destructiveness. If we accept the Freudian schema of two opposing, but related drives, unbinding always presents a danger. It is a psychic process that usually results in progressive and serious diseases which can lead to death. This is particularly true of autoimmune and cancerous diseases. This process usually develops in subjects with a non-neurotic ego organization, but especially in subjects who have suffered psychic traumas that have reactivated deep and early narcissistic wounds.

In all cases, the dimension of narcissistic loss is present and is the underlying cause of a disturbance of mentalization, whether momentary or lasting. This narcissistic loss generates a state of drive unbinding that modifies the whole psychosomatic equilibrium of the subject.

During the course of its evolution, psychopathological changes develop first; subsequently, physio-pathological changes occur.

On the psychic level, a number of symptoms are grouped together under the term "operational life" (vie opératoire): a certain quality of depression, essential depression, and a certain quality of thinking termed "operational" thinking (pensée opératoire).

\section{Essential depression}

This depressive modality is characterized by the absence of symptomatic expressions. It was described by Pierre Marty in 1966 and is defined by a general lowering of the life tonus, without an economic counterpart. Indeed, we do not find in the essential depressive experience either sadness or feelings of guilt or melancholic self-accusation. 
Essential depression is revealed by its symptoms of negativity and fatigue. Patients do not call themselves sad, but weary. They do not want anything, they are "anhedonic" (= without pleasure).

From a metapsychological point of view, this essential depression bears witness to a libidinal loss, narcissistic as well as object-related.

\section{Operational thinking}

This is a current, factual mode of thought, unrelated to fantasy activity or symbolization. It accompanies the facts more than it represents them.

It is, in fact, a form of not-thinking, insofar as it has lost its links with its drive source. It is to be distinguished from obsessional thinking. From a metapsychological point of view, the hypercathexis of perceptual activity, on which it is based, is aimed at defending the subject from the effects of traumatic distress. Operational thinking is a defense against trauma.

Operational life can become a chronic state or take the form of a momentary and reversible critical state. It usually represents a fragile and unstable modality of psychosomatic equilibrium. In pronounced forms of operational life, one often observes a deterioration in the quality of the superego and its substitution by a powerful idealizing system, which Marty described as the Ideal Ego.

The Ideal Self of narcissistic omnipotence, according to Marty's definition, is a trait of behavior defined by its excessiveness. It is based on the inexhaustible demands of the subject, vis-à-vis himself as well as vis-à-vis others.

The major interest in locating an Ideal Self in a patient lies in the absence of regressive capacities and psychic passivity that it implies, which constitute a risk of psychic and somatic collapse.

Once installed, the operational mode of life depends on the auspicious quality of the environment surrounding the patient and, in particular, the establishment of a suitable psychoanalytic treatment framework. Given the reduction of mental capacity for integrating traumatic events that it implies, it always represents a major risk of somatic disorganization.

Now that I have concluded this theoretical presentation of the essential theses of the Paris Psychosomatic School, I will look at some clinical examples.

First, concerning the concept of "disease", I opt for a conception already developed by Hegel (1818) in section III of The Philosophy of Nature. Hegel had this amazing formula: "A stone does not fall ill” (Hegel, 1818, p. 311), a dead organism whose existence is purely objective, the stone cannot be ill since it vanishes in its own negation, it exists or it decomposes; it differs from 
a human being endowed with subjectivity, who is affected by disease in his being-in-the-world and his identity.

In this sense, there is no such thing as psychosomatic illness in my opinion; it is the human being who, by definition, constitutes a somatopsychic unity.

Wanting to think of illness as affecting the soma alone, and therefore without any repercussions on psychic life, seems absurd.

The question of causality is more complex. In my opinion, there is no purely psychogenetic somatic disease. Somatic illness, whatever it may be, serious or benign, is the result of an infinite number of factors and occurs at a given moment in a subject's life. The flexibility of the human genetic program is such that even a genetically programmed cancer cannot be chronologically foreseen. In this last case, life events, fantasy life, the psychic history of the subject and his/her capacities for mental elaboration will, in my opinion, be factors of acceleration or delay in the processes leading up to the outbreak of the disease. However, a breast cancer that appears at age 35 is an entirely different event from one that appears at age 65 .

I will refer here to a neurobiologist, Alain Prochiantz, who, in his (1989) book La Construction du cerveau, reacts against cybernetic formalism to suggest that before thinking of the brain as a sophisticated complex for processing information, we need to see it as a living reality, the result of the evolution of the species as much as of individual history.

That a certain type of depression called essential (described above) facilitates the somatic disorganization of the subject seems to me obvious. But I would certainly not go so far as to say that all essential depression leads to the state of illness, and even less would I suggest that essential depression is a causal factor, as one sometimes reads or hears.

Personally, the question of aetiology is of little interest to me, and in any case, much less than that of the process of healing or deterioration of a disease in progress. It seems to me that the study and analysis of the latter should be the true object of research of the psychoanalyst-psychosomaticist who is faced by patients suffering from somatic affections.

Prochiantz shows that this great flexibility in the genetic programming of man renders him "an extreme individual, and at the same time the most individual and the most social of animals ... who cannot be reduced to any programming that cannot account for the fantasy" (1989, page 79).

The soma's ailments are part of life's events, but even when inscribed in the genes or neuronal structure of the brain, the disorders or pleasures of the human being are infinitely diverse and subject to randomness because they are always subject to a singular history. 


\section{Clinical illustrations}

Three short clinical vignettes seem to illustrate this type of work:

These patients were in treatment, one for 5 years, the other two for about 4 years, at the Paris Institute of Psychosomatics, thus free of charge. They were referred by their doctors who continue to follow them elsewhere, which is a condition sine qua non of their support by IPSO.

It should also be understood that patients referred to the Institute do not come voluntarily. They arrive "on prescription" and accept psychotherapy as yet another treatment. It is necessary therefore to interest them in their psychic life and help them begin to take an interest in themselves, to make them understand that there is no life without history and no human history that is not worthy of interest.

There is no question of leaving them in an "analytical silence" that could be traumatic.

The therapist must be able to follow his patients with attentive benevolence. We must also develop what I have called "the art of conversation", encouraging the patient to associate, making links, urging him/her to think, making suggestions to him/her without imposing our ideas. For example: a patient told me without any affect that a small dog had been crushed by a bus in front of her. I said to her: "In your place, I would have probably been turned inside out". Another told me coldly about a horrible dream; I asked him if this dream had made him afraid and followed this up by saying, "It's a very scary dream".

\section{Mr. X:}

The patient was a 30-year-old man; his cardiologist was worried because he was not certain that he was taking his beta-blockers regularly. He was a seriously hypertensive patient whose "operational" mode of functioning was obvious and typical. He habitually told me the facts and events of the week in chronological order. I could only listen to him patiently and empathically and tried to make him reflect on his actions, by saying, for example, "Have you wondered why you said that?" In the first years of the analysis he was unable to tell me anything about his history. He lived in the present. He had no memories and he had never apparently experienced either affects or anguish. I realized after a few months that he had explosions of destructive anger that often ended up with him being taken to the police station for committing criminal acts. 
The differential diagnosis was clearly one of psychopathy. And yet that was not in fact what was involved; rather, it was an "operational" state of mind which collapsed his psychic topography and implied a total regression of the superego.

As he was incapable of any psychic work of thinking, there were only two solutions for this man: either somatic issues (= hypertension), or behavioral issues, hence the violence. One day he told me that he had been arrested by a plainclothes policeman for kicking a car and was driven once again to the police station. This policeman had given him a physical reprimand and then kept him in his office for a long time, telling him that if he did it again, he would have answer to him. "I won't let you go", he told him. During this story, I noted that Mr. X looked radiant, and I told him so. The patient was surprised and answered, "Yes, maybe; he's a chic type, this cop." I pointed out to him that perhaps he had met a father figure who would not let him down, unlike his own father who died when he was born. A father figure who would reprimand him, but still be there for him. For the first time since I had known him, he was moved, saying "Yes, I did not meet my father even once".

From that moment onwards Mr. X was able, from time to time, to tell me about his childhood.

He knew nothing about his father and he did not tell me anything about his mother. I noticed that he often spoke with hatred about his female colleagues "who humiliated him", and I asked him one day if his mother too had humiliated him.

He told me horrible stories about when he had wet himself at night and she would take him to school with his dirty pants on his head. I was deeply moved and told him that it was difficult to recall such atrocious moments. I would say that during this session there was a real sharing of affect between him and me.

Several months went by, then one morning he sat down, looked at me, and remained silent. He contorted himself like a terrified child. I asked him what was going on. "I'm afraid," he told me. "You're afraid here, now?" I asked. He did not answer. I insisted, "Are you afraid of me?" "Yes", the patient told me, "I feel that you are not the same, you are angry".

Now I had in fact been preoccupied that morning and indeed was angry about an administrative procedure I had to redo. But I was very struck by the unconscious perception by my patient of my psychic state, albeit put aside at that moment. I could see how much the little boy must have been on the watch for his mother's "moods"; she was probably immature and unhinged. I shared this thought with him, and he started sobbing uncontrollably. 
After these two moments we were able to begin a more classical psychoanalytic psychotherapy that lasted for years.

\section{Mrs. Y:}

This was a 40-year-old single woman without children who suffered from severe asthma which prevented her from working. Her psychic organization was typically borderline, but there were long, very long, periods of "operational" functioning.

For months and months, she had been clinging to my gaze and would launch into either factual descriptions of her life or hateful, furious rants about the weather, the government, social security, her doctors, etc.

Her speech was factual, repetitive, angry and hateful, and was difficult to interrupt and endure. I knew I had to listen patiently, but was somewhat desperate.

One day, after having complained violently about her allergist, the secretary, and my silence, she began to describe at length a new intercostal pain, which she had experienced since the weekend. She had been diagnosed with a cracked rib due to her coughing attacks and to high doses of corticosteroids.

She had been talking angrily for almost 20 minutes. I felt worried and my mind was wandering; I thought then of a dear friend who had died of an embolism; she had not consulted anyone about this pain because she believed, being a doctor herself, that it was an intercostal fracture.

I was overwhelmed by a powerful affect of sadness. A few seconds later, the patient moved, breathing loudly; it seemed to me that she was having an asthma attack. She got up, as if to leave, and screamed: "There, it is all your fault... I'm having a crisis again... You let me down". I asked her to sit down and went on to talk to her at length: I told her that she was right, I was thinking of someone else whom she had brought to my mind, but that we needed to think together about her intolerance when she felt unable to control the thoughts of another person entirely.

At this moment, the patient began to breathe better and I offered a construction telling her that it was likely that she was making me have a similar experience to that which she had suffered in the distant past, that of being invaded and having her thoughts controlled... She cried for the first time.

She went on to talk to me for a long time, over several months, about an invasive mother who thought for her, was cold or hungry for her, and knew better than she did what she was feeling. But above all, this mother had harassed her by saying things like: "Who are you thinking about? Stop 
dreaming, be present and listen to me". Following the introduction of a third party and of her history, psychoanalytic work could finally begin. Mrs. Y was finally able to think back to her childhood and then of herself as a subject. These changes were the beginning for her of a real transformation.

\section{Miss Z:}

Miss $Z$ was a woman about 35 years old. She had had chronic pain since the death of her beloved father. This was a somewhat pathological state of mourning, as her 76-year-old father had died of a malignant lymphoma more than 18 months previously. He had been suffering for 7 years.

She had remained close to him and cared for him with love and devotion, replacing her mother in the role of the companion of a very ill man. I noted that in doing so she had sacrificed her life as a girl to her father, an idea she rejected angrily.

Faced with this very Oedipal picture, I wondered whether Miss Z was not presenting a hysterical conversion pain. However, she had been diagnosed with a real neck pain, but her pain was radiating into her right shoulder, and she constantly complained that her shoulder was "heavy".

The idea came to me that this was a post-traumatic pain, as if she had had an accident, as if her father's death had not touched her physically, but devastated her psychically.

Intrigued by the way she spoke about this persistent pain, I once asked her if "the right shoulder" could have had a particular function or interest. Miss $\mathrm{Z}$ told me that previously she had played tennis, making heavy use of her right shoulder. But she had dropped the tennis when her father fell ill. Then during walks in the park and later at the hospital with her father, she had carried her bag across her left shoulder, while her father usually leant on her right shoulder.

I pointed out to her that feeling her "heavy and painful" shoulder was perhaps a way of continuing to feel her father leaning heavily on her shoulder. In this way she was keeping him alive through her pain.

This question opened many associative paths that allowed us to explore her passionate love for her father and also her ambivalence towards him; by falling ill, he had ruined the life of his daughter.

Her grief also represented a living reproach against her mother who had moved aside, thereby leaving her to fill not only her place but also to bear the full weight of the father's illness. The pain completely disappeared in the first six months of psychoanalytic work. 
The sociologist David Le Breton has spoken in a remarkable way about pain in two exciting books: Anthropologie de la douleur (1995) and Expérience de la douleur (2010). He shows with subtlety the complexity of the way patients cathect their pain. He speaks of "pains of loyalty" (Le Breton, year, 1995), pains in which the identification with a close relative who has died is achieved by reproducing the same or similar pains to those the deceased person endured.

The case of my patient was a little more complex, it was not a case of being in pain like the father, but about keeping him alive at the price of pain, a compromise that combined her love and hatred.

Le Breton also insists on "the meaning of pain" (2010, p. 54); for instance, in initiatory rites pain is very well tolerated because it has a purpose. In the same way the chosen form of pain, be it tattoos, piercings, violent sports, body art, is experienced as an expression of self-identity. We can see in everyday life how much sportsmen cathect the muscular pains that they proudly exhibit.

Conversely, the pain of disease is "meaningless", opaque, without purpose; it is then coupled with psychological suffering and a feeling of devaluation that disorganizes the organization of the subject.

\section{By way of conclusion}

The care of these patients who are suffering both in their bodies and also often at the level of their dignity by psychosomatic psychoanalysts does not replace conventional medical treatments or other forms of care.

It aims to support healing processes by allowing them to integrate the illness into their psychic life. It is not a matter of accepting it - because it is unacceptable - but rather of giving it a meaning that it does not have in itself, yet that can be given to it during psychoanalytic work.

Illness and pain break "the silence of the body", the ignorance of the physiological processes that take place in us. They are opaque and noisy and deserve to be heard on many levels.

All pain or sickness is also psychological suffering; like Le Breton, I would say that "the human condition is bodily". 


\section{REFERENCES}

AISENSTEIN, M. (2006). The indissociable unity of psyche and soma Int J Psychoanal, 87:667-680.

AISENSTEIN, M. (1993). Psychosomatic solution or somatic outcome: the man from Burma. Psychotherapy of a case of haemorrhagic rectocolitis Int J Psychoanal, 74(2):371-381.

AISENSTEIN M. (2008). Beyond the dualism of psyche and soma The Journal of the American Academy of Psychanalysis and dynamic Psychiatry, 36:103-125.

FREUD, S. (1914). On Narcissism: an introduction. SE XIV. Hogarth Press, London, pp. 69-102.

FREUD, S. (1920). Beyond the Pleasure Principle. SE XVIII. Hogarth Press, London, pp. 1-66.

FREUD, S. (1923). The Ego and the Id. SE XIX. Hogarth Press, London, pp 3-63.

FREUD, S (1910-12). Correspondance with S. Ferenczi (volume II). Calman-Levy, Paris, 1995, pp. 124-125.

FREUD, S. (1938) An Outline. SE XVIII. Hogarth Press, London, pp. 141-205.

HEGEL, G.W. (1818). The Philosophy of Nature. Oxford University Press, 1970.

LE BRETON, D. (1995). Anthropologie de la douleur [Anthropology of physical pain]. Métaillé, Paris.

LE BRETON, D. (2010). Expérience de la douleur [Experiencing physical pain]. Métaillé, Paris.

PROCHIANTZ, A. (1989). La construction du cerveau. [The Construction of the Brain]. Hachette, Paris. 